\title{
PENGENALAN KODE ETIK PENULISAN KARYA TULIS ILMIAH SEBAGAI UPAYA PENINGKATAN KEMAMPUAN MAHASISWA DALAM MENYUSUN MAKALAH
}

\author{
Noer Saudah'), Yuni Susilowati²), Nurul Hikmah ${ }^{3)}$, Rina Rohayu ${ }^{4)}$, Risna Zubaidah ${ }^{5}$, \\ Syaharuddin ${ }^{6}$ ) \\ 1)Program Studi Keperwatan, STIKes Bina Sehat PPNI, Mojokerto, Jawa Timur, Indonesia \\ ${ }^{2)}$ Program Studi Keperawatan, STIKes Yatsi, Tangerang, Banten, Indonesia \\ 3)Program Studi PGSD, Universitas Widya Gama Mahakam, Samarinda, KalimantanTimur, Indonesia \\ 4) Imu Hukum, Universitas Muhammadiyah Mataram, Mataram, NTBIndonesia, \\ 5)Administrasi Rumah Sakit, STIKeS Ar Rahma Mandiri, Pasuruan, Jawa Timur, Indonesia, \\ ${ }^{6}$ Pendidikan Matematika, Universitas Muhammadiyah Mataram, Mataram, NTB, Indonesia \\ Corresponding author: Syaharuddin \\ E-mail: syaharuddin.ntb@gmail.com
}

Diterima 31 Agustus 2021, Direvisi 09 September 2021, Disetujui 09 September 2021

\begin{abstract}
ABSTRAK
Kegiatan ini bertujuan untuk meningkatkan pemahaman mahasiswa tentang jenis-jenis dan susunan karya tulis ilmiah, pedoman penulisan karya tulis ilmiah, dan penelusuran database pengindeks sebagai sumber referensi. Kegiatan workshop ini dilakukan secara luring di Akademi Dakwah Indonesia Provinsi NTB dengan peserta berjumlah 10 orang. Evaluasi kegiatan dilakukan menggunakan angket skala Likert 5 option yang berisi lima pernyataan positif. Hasil evaluasi menunjukkan bahwa tingkat pemahaman mahasiswa terhadap materi yang telah disampaikan ratarata sebesar $85,2 \%$. Pemahaman tentang karya ilmiah yang telah diperoleh semoga dapat diterapkan di masa mendatang guna menghasilkan karya tulis yang berkualitas dan bermutu.
\end{abstract}

Kata kunci: kode etik publikasi; karya tulis ilmiah; menyusun makalah

\begin{abstract}
This activity aims to improve students' understanding of the types and arrangements of scientific papers, guidelines for writing scientific papers, and tracing indexing databases as reference sources. This workshop activity was conducted offline at the Indonesian Dawah Academy of NTB Province with 10 participants. Evaluation of activities is carried out using the Likert 5 option scale questionnaire which contains five positive statements. The evaluation results showed that the level of student understanding of the material that has been delivered is on average $85,2 \%$. Understanding of scientific work that has been obtained hopefully can be applied in the future to produce quality and quality writing
\end{abstract}

Keywords: code of ethics of publications; scientific papers; drafting papers

\section{PENDAHULUAN}

Makalah adalah uraian tertulis yang

dikemukakan untuk mendapatkan pembahasan yang lebih lanjut (Nastiti \& Yuliarti, 2020). Makalah merupakan salah satu jenis karya ilmiah yang paling popular. Hal ini karena tidak ada mahasiswa yang tidak pernah menyusunnya. Jenis karya ilmiah lain yakni skripsi, tesis, disertasi, paper, artikel ilmiah, dan lembar kerja (Saman \& Bakhtiar, 2018). Namun lembar kerja jarang disebutkan sebagai karya ilmiah karena hampir tidak pernah disusun oleh mahasiswa selama mengenyam pendidikan tinggi.

Salah satu kegiatan rutin mahasiswa ketika menempuh pendidikan di jenjang perguruan tinggi adalah membuat makalah.
Kegiatan ini dilakukan sebagai ajang latihan menuntun mahasiswa agar menjadi insan yang kritis dengan dasar literasi yang kuat (Yudhyarta et al., 2021). Setiap mahasiswa atau kelompok tidak mudah menyusun makalah jika tidak didahului kajian teori yang baik dan maksimal. Karena kuantitas membaca referensi akan berpengaruh pada kualitas dan ketajaman berpikir serta urutan penyampaian materi kepada mahasiswa yang lain di kelasnya (Juniarti, 2019), (Kristanto, 2018)

Terlepas dari itu, tidak sedikit mahasiswa yang pandai dalam retorika namun tidak professional dalam menyusun karya ilmiah berupa makalah yang baik dan sesuai peraturan yang berlaku (Lilis Amaliah 
Rosdiana, 2020). Sementara, kemampuan menulis mahasiswa merupakan tujuan utama yang harus dibangun sebagai langkah strategi agar mahasiswa sukses dalam menyusun tugas akhir di kemudian hari (Sari \& Asmendri, 2020). Karena menyusun makalah hakikatnya merupakan langkah awal seorang mahasiswa memahami kode etik atau tata tertib dalam menyusun tugas akhir baik skripsi maupun paper ilmiah yang nantinya akan dipublikasikan ke jurnal.

Hasil observasi dan pemeriksaan awal terhadap karya ilmiah berupa makalahmakalah yang telah disusun oleh mahasiswa Akademi Dakwah Indonesia cabang Provinsi Nusa Tenggara Barat (NTB), rata-rata masih terdapat kekurangan yang harus diperbaiki. Kekurangan atau kesalahan tersebut meliputi (1) artibut pada bagian cover, (2) komponen yang harus disampaikan pada bagian prakata, (3) tata tulis isi makalah pada bagian pembahasan seperti konsistensi jenis huruf dan spasi, (4) teknik menulis rujukan dalam isi makalah, (5) teknik menulis referensi. Secara umum, kesalahan-kesalahan yang sering dilakukan mahasiswa ketika menyusun makalah yakni (1) kesalahan penggunaan Ejaan Bahasa Indonesia (EBI) di antaranya: pemakaian huruf; penulisan kata (kata dasar, kata berimbuhan, dan kata depan); dan penggunaan tanda baca (Nastiti \& Yuliarti, 2020), (Tussolekha, 2019); (2) kesalahan menyusun paragraph sehingga menjadi pembahasan yang baik (Nugroho et al., 2019), (Ardianto, 2018); dan (3) rujukan yang minim dan tidak update (Yudhyarta et al., 2021), (Supianti, 2018); dan (4) tingginya tingkat plagiasi yang dilakukan mahasiswa (Saddam, et al., 2021).

$$
\text { Kekurangan atau kesalahan- }
$$

kesalahan tersebut tentu harus diperbaiki. Oleh sebab itu, tim Abdimas menawarkan solusi agar mahasiswa dilatih untuk menyusun makalah yang baik dan berkualitas. Makalah yang baik dan berkualitas tentu harus didasari oleh sumber referensi yang update (Windarto et al., 2018). Oleh sebab itu, pelatihan menelusuri sumber referensi secara online juga penting disampaikan agar mahasiswa bisa melakukan eksplorasi yang lebih luas dan pembahasan yang tajam ketika menyusun makalah (Syaharuddin, Mandailina, Pramita, et al., 2021), (Sukarma et al., 2017), (Cahyani, 2010).

Dari penjelasan tersebut, tujuan dilakukan kegiatan ini adalah (1) untuk meningkatkan pemahaman mahasiswa tentang teknik menyusun karya ilmiah yang baik dan benar; (2) meningkatkan softskill mahasiswa dalam melakukan penelusuran sumber referensi dalam menyusun makalah; dan (3) mengurangi tingkat kesalahankesalahan yang sering dilakukan mahasiswa dalam menyusun makalah. Harapannya, output kegiatan ini akan berdampak pada peningkatan pemahaman mahasiswa dalam menyusun tugas akhirnya.

\section{METODE}

Kegiatan ini dilaksanakan pada tanggal 19 Agustus 2021 secara luring. Peserta sebanyak 10 orang merupakan mahasiswa Akademi Dakwah Indonesia cabang Provinsi Nusa Tenggara Barat. Adapun tahapan pelaksanaan sebagai berikut.

\section{Workshop Karya Tulis IImiah}

Pada sesi ini pemateri menyampaikan beberapa hal penting tentang karya tulis ilmiah yakni (1) jenis-jenis dan susunan karya tulis ilmiah, pedoman penulisan karya tulis ilmiah, dan database pengindeks sebagai sumber referensi, (2) melakukan simulasi pencarian sumber rujukan di Google Scholar, DOAJ, Sciencedirect, dan lain-lain.

\section{Diskusi dan Tanya Jawab}

Pada sesi ini, pemateri melakukan pemeriksaan terhadap contoh-contoh makalah yang pernah dibuat oleh mahasiswa, melakukan diskusi terbuka dan tanya jawab terhadap kelemahankelemahan yang perlu diperbaiki untuk pembuatan karya tulis selanjutnya.

3. Evaluasi

Evaluasi dilakukan untuk mengukur tingkat pemahaman mahasiswa terhadap workshop yang telah dilakukan. Pemateri menggunakan Google Form yang berisi pernyataan-pernyataan positif dengan skala Likert 5 option. Hasil angket dianalisis menggunakan statistika deskriptif untuk melihat tingkat persentase pemahaman mahasiswa.

\section{HASIL DAN PEMBAHASAN}

\section{Workshop Karya Tulis IImiah}

Acara workshop langsung dibuka oleh Direktur Akademi Dakwah Indonesia Cabang Provinsi NTB. Dalam sambutannya, beliau mengapresiasi kegiatan ini. Karena dapat membantu mahasiswa di masa mendatang untuk membangun literasi yang baik guna menghasilkan karya tulis yang bermutu. Setelah acara sambutan, pemateri langsung menyampaikan materi terkait (1) jenis-jenis dan susunan karya tulis ilmiah. Pemateri menyampaikan bahwa karya tulis ilmiah banyak macamnya seperti makalah, laporan hasil penelitian, skripsi, tesis, disertasi, paper ilmiah, artikel ilmiah. Selanjutnya, pemateri 
menyampaikan pedoman penulisan karya tulis ilmiah yang tidak lepas dari pedoman skripsi masing-masing universitas, karena setiap lembaga pendidikan memeliki pedoman masing-masing yang berbeda dengan lembaga pendidikan lainnya. Pada kesempatan ini, pemateri menyampaikan dari aturan penulisan cover, prakata, daftar isi, daftar tabel, daftar gambar, aturan setiap bab, sampai daftar pustaka dan lampiran. Terakhir, pemateri menyampaikan tentang database pengindeks sebagai sumber referensi. Hal ini penting disampaikan karena syarat dalam menulis karya ilmiah harus ditunjukkan rujukan atau referensi dari hasil-hasil penelitian yang relevan. Adapun proses penyampaian materi terlihat pada Gambar 1 berikut.

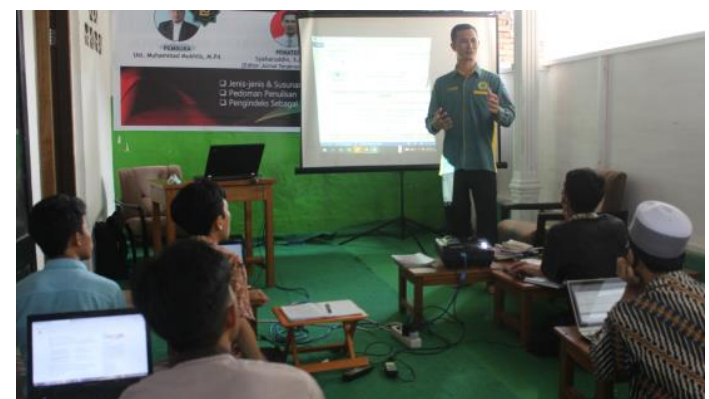

Gambar 1. Kegiatan Penyampaian Materi

Salah satu kegiatan yang membawa dampak positif bagi mahasiswa adalah mereka mampu melakukan penelusuran sumber rujukan melalui database pengindek Google Scholar, DOAJ, Sciencedirect, dan berbagai macam sumber yang beredar di internet yang bisa diakui sebagai rujukan dalam menyusun karya ilmiah, khususnya makalah, skripsi, tesis, dan disertasi yang akan ditempuh mahasiswa di setiap jenjangnya.

\section{Diskusi dan Tanya Jawab}

Satu hal menarik saat sesi diskusi dan tanya jawab yakni adanya proses pemeriksaan serta pemberian saran terhadap hasil makalah-makalah yang pernah disusun oleh mahasiswa selama ini. Pemateri memberikan saran perbaikan untuk tidak diulangi kesalahan-kesalahan di masa mendatang. Mahasiswa aktif bertanya tentang solusi perbaikan yang perlu dilakukan, terutama kesalahan-kesalahan yang sering terjadi atau dilakukan mahasiswa sebagai pemula dalam menyusun karya ilmiah. Adapun suasana diskusi dan tanya jawab terlihat pada Gambar 2 berikut.

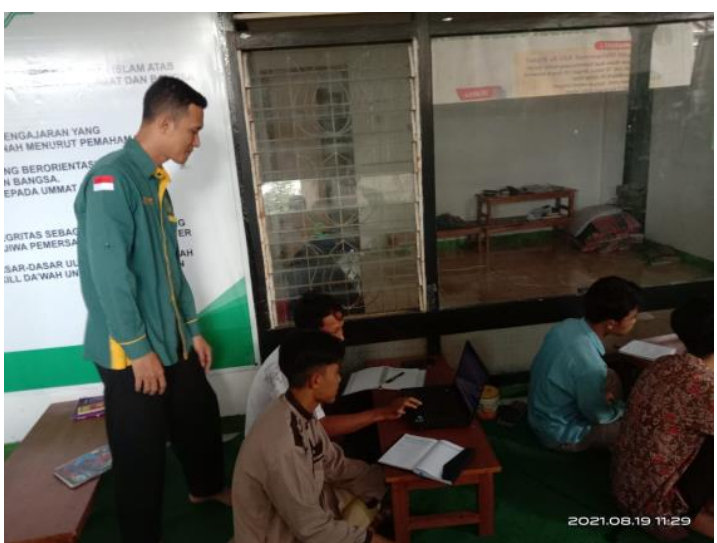

Gambar 2. Suasana Diskusi dan Tanya Jawab

\section{Hasil Evaluasi Kegiatan}

Pada tahap akhir, tim Abdimas melakukan evaluasi terhadap pelaksanaan kegiatan. Evaluasi dilakukan menggunakan google form berisi tujuh pertanyaan dengan skala Likert 5 option. Adapun hasil evaluasi terlihat pada Tabel 1 berikut.

Tabel 1. Hasil Evaluasi Kegiatan

\begin{tabular}{|c|c|c|}
\hline No & Indikator & $\begin{array}{c}\text { Penguasaan } \\
(\%)\end{array}$ \\
\hline 1 & $\begin{array}{l}\text { Saya memahami } \\
\text { jenis-jenis karya } \\
\text { ilmiah }\end{array}$ & $92 \%$ \\
\hline 2 & $\begin{array}{l}\text { Saya memahami } \\
\text { proses penyusunan } \\
\text { karya ilmiah }\end{array}$ & $78 \%$ \\
\hline 3 & $\begin{array}{l}\text { Saya memahami } \\
\text { pedoman penulisan } \\
\text { tiap item dalam } \\
\text { makalah }\end{array}$ & $92 \%$ \\
\hline 4 & $\begin{array}{l}\text { Saya memahami } \\
\text { fungsi dan cara } \\
\text { menelusuri sumber } \\
\text { rujukan di database } \\
\text { pengindek }\end{array}$ & $80 \%$ \\
\hline 5 & $\begin{array}{l}\text { Saya memahami } \\
\text { kelemahan atau } \\
\text { kekurangan yang } \\
\text { selama ini dilakukan } \\
\text { dalam menyusun } \\
\text { karya ilmiah } \\
\end{array}$ & $84 \%$ \\
\hline & Rata-rata & $85,2 \%$ \\
\hline
\end{tabular}

Dari Tabel 1 diperoleh informasi bahwa tingkat pemahaman mahasiswa terhadap materi yang telah disampaikan rata-rata sebesar $85,2 \%$. Selama pelaksanaan kegiatan, hampir tidak ditemukan kendala yang berarti. Karena mahasiswa mengikuti kegiatan dengan seksama mulai proses penyampaian materi, latihan penelusuran sumber rujukan, diskusi dan tanya jawab, sampai penutup. 


\section{SIMPULAN DAN SARAN}

Kegiatan ini telah dilaksanakan dengan baik, peserta mengikuti dengan antusias, termasuk berperan aktif saat diskusi dan tanya jawab. Hasil evaluasi menunjukkan bahwa tingkat pemahaman peserta mencapai rata-rata sebesar $85,2 \%$. Hasil ini diperoleh karena selama kegiatan berlangsung hampir tidak ditemukan kendala yang berarti. Peningkatan pemahaman mahasiswa tentang karya tulis ilmiah sangat penting, karena pemerintah telah menetapkan bahwa setiap lulusan diploma, sarjana bahkan pascasarjana harus menyusun karya tulis ilmiah dan mempublikasikannya. Oleh sebab itu, direkomendasikan untuk kegiatan selanjutnya, secara implisit disampaikan teknik menyusun karya ilmiah berupa paper yang akan disubmit ke sebuah jurnal.

\section{UCAPAN TERIMAKASIH}

Tim penulis mengucapkan Terima Kasih kepada Pimpinan Fakultas Keguruan dan IImu Pendidikan, UM Matarm yang telah memberikan ijin dan support sehingga kegiatan ini berjalan dengan lancar. Selanjutnya, kepada mahasiswa Akademi Dakwah Indonesia cabang Provinsi NTB yang sudah antusias mengikuti kegiatan ini. Semoga ilmu yang diperoleh dapat diterapkan secara maksimal di masa mendatang.

\section{DAFTAR RUJUKAN}

Ardianto, A. (2018). Pemakaian Bahasa Indonesia Dalam Karya Tulis Mahasiswa (Suatu Kajian dengan Pendekatan Analisis Wacana). Jurnal Ilmiah Iqra', 7(1). https://doi.org/10.30984/jii.v7i1.601

Cahyani, I. (2010). Peningkatan Kemampuan Menulis Makalah Melalui Model Pembelajaran Berbasis Penelitian pada Mata Kuliah Umum Bahasa Indonesia. Sosiohumanika: Jurnal Pendidikan Sains Sosial Dan Kemanusiaan, 3(2), 175-192.

Juniarti, Y. (2019). Pentingnya keterampilan menulis akademik di perguruan tinggi. Prosiding Sembadra Universitas Sriwijaya, 2(1), 185-189.

Kristanto, V. H. (2018). Metodologi Penelitian Pedoman Penulisan Karya Tulis IImiah (KTI). In Deepublish Publisher (p. 66).

Lilis Amaliah Rosdiana. (2020). Kesalahan Penggunaan Ejaan Bahasa Indonesia (EBI) Pada Karya IImiah Mahasiswa. Bahtera Indonesia; Jurnal Penelitian Bahasa Dan Sastra Indonesia, 5(1), 1-11. https://doi.org/10.31943/bi.v5i1.58

Nastiti, A., \& Yuliarti, Y. (2020). Analisis Kesalahan Berbahasa pada Makalah Mahasiswa Sekolah Tinggi IImu Ekonomi
(STIE) Semarang. ALFABETA: Jurnal Bahasa, Sastra, Dan Pembelajarannya, 3(2), 50-57. https://doi.org/10.33503/alfabeta.v3i2.108 3

Nugroho, R. D., Suryawati, C. T., \& Zuliastutik, H. (2019). Analisis Kesalahan Dalam Penulisan Karya IImiah Mahasiswa Jepang Dalam Pembelajaran BIPA. Jurnal Pendidikan Bahasa Dan Sastra, 18(2), 193-209. https://doi.org/10.17509/bs_jpbsp.v18i2.1 5508

Saman, A., \& Bakhtiar, M. I. (2018). Karya Tulis IImiah Bagi Mahasiswa STKIPi Matappa Kabupaten Pangkep. Jurnal Terapan Abdimas, 3(1), 39. https://doi.org/10.25273/jta.v3i1.2165

Sari, M., \& Asmendri. (2020). Penelitian Kepustakaan dalam Penelitian Pendidikan IPA. Jurnal Penelitian Bidang IPA Dan Pendidikan IPA, 6(1), 41-53.

Sukarma, I. K., Prayogi, S., Muliadi, A., Firdaus, L., Samsuri, T., Mirawati, B., Sabda, D., Prasetya, B., \& Karmana, I. W. (2017). Pelatihan Penulisan Karya Tulis IImiah Penelitian Tindakan Kelas ( Ptk ). Jurnal Lumbung Inovasi, 2(1), 68-71.

Supianti, I. I. (2018). Mendeley Sebagai Alat Bantu Dalam Penyusunan Referensi Artikel. Prosiding Seminar Nasional Dan Workshop "Penulisan Dan Publikasi Artikel IImiah,"168-177.

Syaharuddin, Mandailina, V., Pramita, D., Rahmaniah, R., Rosada, \& Negara, H. R. P. (2021). Peningkatan Kualitas Publikasi Mahasiswa dan Sitasi Karya Ilmiah Dosen Melalui Workshop Managemen Software Mendeley. Community Development Journal: Jurnal Pengabdian Masyarakat, 2(1), 8-13.

Syaharuddin, S., Mandailina, V., Saddam, S., Negara, H. R. P., Satriawan, R., \& Ibrahim, M. (2021). Minimalisasi Tingkat Plagiat Karya IImiah Mahasiswa Melalui Workshop Software Plagiarism Checker X. Bakti Cendana, 4(1), 62-67.

Tussolekha, R. (2019). Kesalahan Penggunaan Ejaan Bahasa Indonesia pada Makalah Karya Mahasiswa. AKSARA: Jurnal Bahasa Dan Sastra, 20(1), 35-43. https://doi.org/10.23960/aksara/v20i1.pp3 5-43

Windarto, A. P., Hartama, D., Wanto, A., Parlina, I., Kurniadi, F., Dr. Syaikhul Falah, SE., M. S., \& Munawwaroh Zahrotul. (2018). Menyusun Makalah yang Baik dan Benar. AKSIS: Jurnal Pendidikan Bahasa Dan Sastra 
Indonesia, 2(2), 1-18.

Yudhyarta, D. Y., Susanti, E., \& Ilyas, M.

(2021). Pelatihan Karya Tulis IImiah Bagi

Mahasiswa. ABDIMASY: Jurnal

Pengabdian Dan Pemberdayaan

Masyarakat, 2(1), 1-10.

https://doi.org/10.46963/ams.v2i1.338 